\title{
CORPO, APRENDIZAGEM E CULTURA DE MOVIMENTO: UMA EXPERIÊNCIA PEDAGÓGICA COM O ENSINO DO CONTEÚDO JOGO NAS AULAS DE EDUCAÇÃO FÍSICA DO IFRN
}

\author{
A. P. Batista', I. P. B. Oliveira², J. P. Melo ${ }^{3}$ \\ ${ }^{1}$ Instituto Federal do Rio Grande do Norte, ${ }^{2}$ UNI-RN, ${ }^{3}$ Universidade Federal do Rio Grande do Norte \\ alison.batista@ifrn.edu.br
}

Artigo submetido em setembro/2012 e aceito em dezembro/2012

\section{RESUMO}

O presente artigo constitui-se de uma reflexão teóricometodológica que teve como objetivo refletir sobre uma experiência pedagógica realizada nas aulas de Educação Física, ministradas no IFRN, no câmpus de Pau dos Ferros, com alunos do 1으 ano do Ensino Médio Integrado. Estabelecemos as seguintes questões de estudo: a) O que entendemos por aprendizagem? b) Que caminhos teórico-metodológicos podem ser traçados para que as aulas de Educação Física possibilitem aprendizagens mais significativas? Esse estudo caracterizou-se como qualitativo, de natureza descritiva. Um dos caminhos vislumbrados leva ao entendimento de que a aprendizagem poderá ocorrer de forma significativa quando estiver imbuída de sentidos/significados que contemplem a reflexão, o contexto, a criatividade, a autonomia, os conhecimentos prévios, o planejamento, entre outras categorias que contribuem ativamente para a superação de práticas mecanicistas e do fazer por fazer.

PALAVRAS-CHAVE: Corpo; Aprendizagem; Cultura de Movimento.

\section{BODY, LEARNING AND CULTURE OF MOVEMENT: AN EDUCATIONAL EXPERIENCE WITH TEACHING THE GAME CONTENT IN PHYSICAL EDUCATION CLASSES OF IFRN}

\begin{abstract}
This paper consists of a theoretical and methodological approach that aimed to reflect on a pedagogical experiment conducted in physical education classes, taught in IFRN, on the campus of the Irons Pau, with students from 1st year of high school integrated. Established the following study questions: a) What do we mean by learning? b) What theoretical and methodological paths can be traced to the Physical Education classes allow for more meaningful learning?
\end{abstract}

This study was characterized as qualitative, descriptive in nature. One path leads to understanding envisioned that learning can occur significantly when imbued with meanings / meanings that include reflection, context, creativity, autonomy, prior knowledge, planning, and other categories that contribute actively to overcome mechanistic practices and by doing do.

KEY-WORDS: Body; Learning; Culture of Movement. 


\section{CORPO, APRENDIZAGEM E CULTURA DE MOVIMENTO: UMA EXPERIÊNCIA PEDAGÓGICA COM O ENSINO DO CONTEÚDO JOGO NAS AULAS DE EDUCAÇÃO FÍSICA DO IFRN}

\section{INTRODUÇÃO}

Ao cursarmos a disciplina "Ateliê de Pesquisa: Corpo e Cultura de Movimento" do Programa de Pós-Graduação em Educação da UFRN fomos provocados e impulsionados a construirmos um diálogo que contemplasse o arcabouço teórico que estava sendo discutido ao longo da disciplina, com o nosso fazer pedagógico e com o objeto de nossos estudos no mestrado em educação do referido programa. O desafio foi motivador e o fruto destas reflexões iniciais será apresentado nas linhas a seguir.

Dessa forma, organizamos a pesquisa a partir de uma intervenção pedagógica realizada no Instituto Federal de Ciência e Tecnologia do Rio Grande do Norte - IFRN, no câmpus da cidade de Pau dos Ferros, localizado na região auto-oeste do estado. Procurando estabelecer interfaces entre os três pontos direcionados pelos professores ministrantes da disciplina, organizamos este estudo que teve como objetivo principal refletir sobre uma experiência pedagógica realizada em aulas do componente curricular Educação Física no Ensino Médio. Para tanto, delimitamos o nosso campo de reflexão em torno do conteúdo jogo como manifestação da cultura de movimento. A fim de aprofundarmos a pesquisa elaboramos as seguintes questões de estudo: a) $O$ que entendemos por aprendizagem? b) Que caminhos teórico-metodológicos podem ser traçados para que as aulas de Educação Física na escola possibilitem aprendizagens mais significativas?

A metodologia da pesquisa constitui-se como um dos elementos primordiais nos estudos investigativos, pois atribui reconhecimento ao estatuto da Ciência. Ela não deve ser compreendida apenas como processo, mas também como produto da investigação. Muitas vezes, as metodologias utilizadas nos estudos são secundarizadas ou até mesmo negligenciadas em publicações de livros e periódicos (SOUZA JR, MELO E SANTIAGO, 2010).

Os autores chamam atenção sobre a importância e a valorização da metodologia utilizada nas pesquisas científicas. Conscientes disso, e após algumas leituras exploratórias e alguns estudos que indicariam os caminhos que deveríamos tomar traçamos como parâmetro a ser seguido o estudo de caráter descritivo, tendo-se a abordagem qualitativa como eixo metodológico.

A pesquisa qualitativa segundo Chizzotti $(1995$, p.79) "parte do fundamento de que há uma relação dinâmica entre o mundo real e o sujeito, uma interdependência viva entre o sujeito e o objeto, um vínculo indissociável entre o mundo objetivo e a subjetividade do sujeito". Essa relação dinâmica ajudará no aprofundamento das discussões construídas ao longo do estudo.

Dentre os tipos de pesquisa qualitativa optamos pela de natureza etnográfica, pois entre as possibilidades de pesquisa que abarcam uma intervenção pedagógica, essa é a que atende com mais clareza os objetivos e motivações para a realização deste estudo. 
A pesquisa etnográfica segundo Martins e Theóphilo (2007, p. 74) "refere-se à descrição de um sistema de significados culturais de um determinado grupo". A intenção da pesquisa não será apenas descrever a realidade, mas intervir sobre ela.

As técnicas de pesquisa foram a observação participante, o registro fotográfico, filmagem, as anotações da nossa impressão das aulas e das conversas com todos os envolvidos no processo investigativo (diário de campo). Esses instrumentos nos auxiliaram e favoreceram o diálogo com os autores que comporam o referencial teórico.

\section{CORPO, APRENDIZAGEM E CULTURA DE MOVIMENTO}

Historicamente o paradigma cartesiano corpo e mente foi marcante na educação e na aprendizagem formal, negando o corpo em detrimento da mente. Nessa perspectiva, o corpo foi disciplinado e controlado, com o intuito de que o ambiente da aprendizagem intelectual dos conteúdos não fosse "perturbado" ou prejudicado por ações motoras ou morais.

Apesar dessa realidade histórica, consideramos que o corpo tem um papel fundamental na educação. Nóbrega (2005, p. 51) ao refletir sobre o corpo no processo educativo afirma que ele "é importante na aprendizagem, mas a escola apela somente ao cérebro, talvez porque não saiba lidar com ele, com sua diversidade e mutabilidade. A aprendizagem é identificada com a imobilidade, por isso o corpo é expulso da ação pedagógica". Essa compreensão de que a imobilidade corporal é um elemento favorável ao processo educativo está agregada a séculos de uma educação dicotômica e fragmentada em que até hoje "existe uma falsa idéia de que o conhecimento se dá estritamente via cognição" (BEZERRA E HERMIDA, 2011, p.80).

A imobilidade corporal é considerada como um pré-requisito para aprendizagem escolar. Um grande exemplo para esta afirmação segundo Zaboli, Bordas, e Lamar (2007, p. 37) é presenciado quando uma criança "conforme o avançar dos anos, é aconselhada a deixar de usar os dedos para auxiliar os cálculos, pois o cálculo deve ser desenvolvido pela esfera mental do sujeito". Acreditamos que a maioria das crianças passou por esta e/ou por outras situações em que os seus corpos foram "extraídos" ou "destituídos" do processo ensinoaprendizagem.

O processo de destituição do corpo do processo educativo acontece ao longo da educação básica, sendo menos evidenciado segundo Bezerra e Hermida (2011, p. 85) na "Educação Infantil, do que em relação aos outros níveis de ensino, pode-se até afirmar que, em muitas escolas, é basicamente neste período que a criança é vista de forma integral". Quando os alunos chegam ao ensino médio percebemos que as suas experiências corporais no currículo escolar limitam-se exclusivamente as aulas de Educação Física e/ou Artes por tais disciplinas serem consideradas responsáveis por trabalhar com a dimensão corporal. Para Zaboli, Bordas, e Lamar (2007, p. 45) isto é "um grande erro histórico, pois a educação escolar não considera o ler, o escrever, o pensar, o contar, o somar como produtos da linguagem corporal".

Sobre as teorias da construção do conhecimento que sustentam as práticas docentes Bracht, $(1999$, p.71) nos alerta que a maioria dessas teorias também são desencarnadas, salvo raras exceções, mas que "inclusive as teorias sobre aprendizagem motora são em parte 
cognitivistas. O papel da corporeidade na aprendizagem foi historicamente subestimado, negligenciado".

Vários autores como Maturana (2001), Assmann (1996, 2007), Serres (2004), Nóbrega (2005, 2010) entre outros estudiosos apresentam discussões contemporâneas que contribuem para a superação do paradigma da educação sem corpo e atribuem ao corpo à premissa do aprender, pois "pensamos e aprendemos com o corpo todo e não apenas com o cérebro e o sistema nervoso" (GREINER, 2005, p.48).

Pontuando esta compreensão temos Maturana (2001) que ao refletir sobre a sua história de vida, em particular, a sua alfabetização, destaca a importância da emoção como elemento imprescindível e motivador para a compreensão da aprendizagem como fenômeno corporal. Ele nos questiona sobre as crianças que são erroneamente taxadas de portadoras de dificuldades de aprendizagem e/ou com problemas de inteligência, testemunhando que somente foi alfabetizado aos 9 anos de idade, motivado pela inveja que sentiu dos seus colegas de turma que tiveram as suas produções expostas. Mais adiante ele relata que "eu não aprendi a ler porque era burro, mas porque não tinha emoção. E freqüentemente, quando a dinâmica emocional da criança não coincide com a nossa, nós a relegamos, a negamos, a consideramos burra, porque seu interesse sua paixão, está em outra parte" (MATURANA, 2001, p.109).

Dessa forma, Assmann (2007, p.29) também se demonstra consonante ao exposto quando afirma que "a aprendizagem é, antes de mais nada, um processo corporal. Todo conhecimento tem uma inscrição corporal. Que ela venha acompanhada de sensação de prazer não é, de modo algum, um aspecto secundário".

Percebendo a aprendizagem como um processo corporal e não somente intelectual, destacamos os investimentos de Dias e Melo (2011, p.43) que baseados nos estudos de Celestin Freinet, afirmam que "a aprendizagem na educação escolarizada torna-se mais significativa quando o aluno a vivencia com seu próprio corpo e não somente imobilizado numa carteira. Afinal, não podemos esquecer que tudo que aprendemos antes de ir à escola é em movimento, brincando".

A imobilidade corporal é um fator preocupante na escola, pois a criança ou o jovem "permanece encerrada quatro horas ou mais, por dia, em salas fechadas e com carteiras exíguas, não mais que meio metro para se movimentar. Leva nisso cerca de doze anos de escolaridade" (FREIRE, 2008, p.67). Entendemos que esta situação vivenciada ao longo da educação básica deva ser considerada uma grande negação do corpo dos nossos alunos, pois percebemos que há um verdadeiro aprisionamento.

A Educação Física é uma das inúmeras possibilidades que a escola tem no sentido de romper com essa imobilidade corporal, sendo assim, este componente curricular tem a responsabilidade de acessar os alunos aos conteúdos que devem ser extraídos e apreendidos da cultura de movimento compreendida segundo Kunz (1998, p. 98) como

Todas as atividades do movimento humano, tanto no esporte como em atividades extra-esporte (ou no sentido amplo do esporte) e que pertençam ao mundo do 'se movimentar' humano, o que o homem por esse meio produz ou cria, de acordo com a 
sua conduta, seu comportamento e mesmo as resistências que oferecem a essas condutas e ações.

Essa cultura de movimento segundo Araújo (2005, p. 61) deve ser vivenciada na escola de forma crítica fazendo-se necessário "que a Educação Física reconheça o acervo de movimentos que o aluno traz para a escola, resultando em um diálogo corporal com seu entorno cultural". Desta forma é importante que o professor procure conhecer o arcabouço teórico que os alunos trazem para escola a fim de dinamizar a aprendizagem das diversas manifestações da cultura de movimento.

Sobre a dinâmica existente entre aprendizagem e conteúdos Neira e Nunes (2009) esclarecem que "a experiência da aprendizagem em si é o que mais configura os conteúdos de ensino. O coletivo docente deve cuidar para a integração da própria cultura experiencial e da cultura dos alunos, com as vivências nas aulas e os conhecimentos que se pretende ensinar" (p.260).

Esses cuidados que o professor deve ter com a integração da cultura experiencial e a cultura dos alunos no tocante a aprendizagem remete-nos ao pensamento de Carvalho e Perez (2002, p. 114-115) quando destacam que

O professor precisa saber que aprender é também apoderar-se de um novo gênero discursivo, o gênero discursivo escolar; para isso, ele precisa saber fazer com que seus alunos aprendam a argumentar, isto é, que eles sejam capazes de reconhecer as afirmações contraditórias, as evidências que não ou não suporte às afirmações, além da capacidade de integração dos méritos de uma afirmação.

Aprofundando um pouco mais sobre a aprendizagem dos conteúdos na Educação Física escolar, recorremos a Araújo (2005, p. 63) que nos aponta

\begin{abstract}
A aprendizagem, na Educação Física Escolar, dar-se-á de forma mais significativa para o sujeito, ao se considerar essas interações da pessoa, com o seu entorno, com o seu ambiente cultural, evidenciando as relações interpessoais, a reciprocidade, o equilíbrio de poder dessas relações e as influencias que ocorrem de maneira bidirecional, no processo de desenvolvimento. Em outras palavras, uma aprendizagem pautada numa concepção de corpos que somos, onde a experiência corporal aponta perspectivas de criatividade, de uma prática significativa, de respeito às diferenças, de interação com os outros e com o mundo.
\end{abstract}

Desafiados a materializar esses investimentos acadêmicos em ações pedagógicas em que o corpo e movimento são considerados elementos fundamentais em nossa prática reflexiva, nos propomos a planejar e a direcionar uma prática de ensino que busca proporcionar aos alunos experiências significativas de aprendizagem. Nesse sentido, André e Passos (2002, p. 181) defendem que para que a aprendizagem seja significativa "ela precisa atender aos objetos do indivíduo, seus interesses e necessidades e ainda envolver sua participação na definição e no desenvolvimento dessas aprendizagens, assim como na sua avaliação". 
Apresentaremos a seguir um relato de experiência com o ensino da Educação Física na escola que acreditamos ser munido de experiências significativas de aprendizagem tanto para os alunos como para os professores envolvidos nesta vivência.

\section{RELATO DE EXPERIÊNCIA}

A experiência pedagógica que estamos trazendo não é inovadora no âmbito da Educação Física, nem tampouco, inédita, pelo contrário é bastante difundida entre as práticas pedagógicas dos professores nos diferentes níveis de ensino da educação básica. Todavia, apresentaremos um olhar fitado na aprendizagem dos conteúdos, buscando trazer elementos que possam favorecer a construção de experiências exitosas para a compreensão de professores e alunos.

A situação didática aconteceu no Instituto Federal de Educação Ciência e Tecnologia do Rio Grande do Norte (IFRN) da cidade de Pau dos Ferros/RN, na qual, o professor foi o pesquisador de sua prática pedagógica. Participaram do estudo cinco turmas de Educação Física do 10 ano do Ensino Médio, distribuídas em duas turmas do Curso de Alimentos, duas do Curso de Apicultura e uma do Curso de Informática, totalizando aproximadamente 200 alunos. Foi sistematizada em seis aulas (duas aulas por encontro) buscando uma compreensão mais ampla do conteúdo jogo. Para isso, nos baseamos no Plano de Trabalho da Disciplina que orienta e traça as diretrizes para o ensino-aprendizagem deste componente curricular na referida instituição.

Em algumas aulas anteriores ao relato sistematizado neste artigo, discutimos com os alunos sobre a cultura de movimento como conhecimento pedagógico da Educação Física, como também, as suas diversas manifestações. Fizemos a experiência de planejar conjuntamente com os alunos e traçamos a forma de como poderíamos contextualizar e relacionar essas primeiras reflexões sobre cultura de movimento, com o conteúdo programático jogo e a realidade dos estudantes.

Sendo assim, as aulas foram planejadas e concebidas em três encontros, a saber: no primeiro discutimos conceitos e características do jogo enquanto manifestação da cultura de movimento; no segundo vivenciamos alguns jogos que materializaram as discussões originadas no encontro anterior e no último encontro, prestigiamos a entrega, apresentação e discussão dos seminários.

O primeiro encontro que teve como tema "jogo: conceito e características". Para este momento traçamos os seguintes objetivos: Discutir o jogo enquanto manifestação da Cultura de Movimento; Conhecer as características e os tipos de jogos; Refletir sobre as diferenças entre jogo, brincadeira e esporte; Apreciar imagens de jogos; Reconhecer a importância do conteúdo jogo para as aulas de Educação Física; Discutir atividade avaliativa em grupo sobre essa temática. Houve desde o início uma preocupação em buscar atender as três dimensões dos conteúdos (conceitual, atitudinal e procedimental), pois segundo Melo (2002, p. 21) "tratar o conhecimento da cultura de movimento na escola não diz respeito somente a lidar com as questões de ordem técnica vinculadas ao saber fazer, mas fomentar nos alunos uma compreensão crítica desse conhecimento, desde sua inserção histórica à sua prática propriamente dita". 
Nesse sentido o papel da Educação Física enquanto componente curricular deve transcender o ensino dos fundamentos e técnicas das diversas manifestações da cultura de movimento, mas ir além, garantindo o direito dos alunos saberem o porquê de estar realizando esta ou aquela atividade/movimento, como também, favorecer a vivência de valores e atitudes. (DARIDO E SOUZA JUNIOR, 2007).

Foram feitos em aulas anteriores alguns questionamentos através de conversas objetivando conhecer um pouco mais sobre o conhecimento dos nossos alunos sobre a temática do jogo, na tentativa de organizamos um programa de aulas voltadas para a discussão de questões presentes no cotidiano deles, pois segundo Aragão (2006, p.146) através "da compreensão do mundo, é possível construir um programa que possibilite um aprendizado significativo".

Dessa forma, nos dispomos a refletir conjuntamente com os alunos questões do tipo: Jogar é coisa de criança? Que tipos de jogos e brincadeiras fizeram parte da infância dos alunos, dos seus pais e avós? O que provocou tais mudanças no hábito de jogar? Quais as diferenças entre jogo e esporte? E vários outros questionamentos que perpassaram a aula. Com relação a este último um aluno provocou uma discussão interessante, quando questionou: "professor quer dizer que é errado falar que vamos assistir ao jogo de futebol na televisão? Pois aquilo lá não é um jogo, mas sim um esporte?" É em momentos como este que o professor sente-se pressionado a dar uma resposta em que nunca antes havia meditado.

Nesta aula dialogada os alunos tiveram a oportunidade de se posicionar criticamente com relação aos conteúdos expostos. E mesmo sendo uma aula dita como "teórica", pois aconteceu na sala de aula, os educandos tiveram a oportunidade de experienciar a dimensão procedimental dos conteúdos quando solicitamos que identificassem na tela "Jogos Infantis do artista Bruegel de 1560" (Figura 1) jogos e brincadeiras que fazem ou fizeram parte da cultura de movimento deles. Neste momento passamos a ter contato com nomenclaturas de jogos e brincadeiras que nunca tínhamos ouvido falar como "Ana Mula", "Barata", entre outras típicas da região oeste do RN.

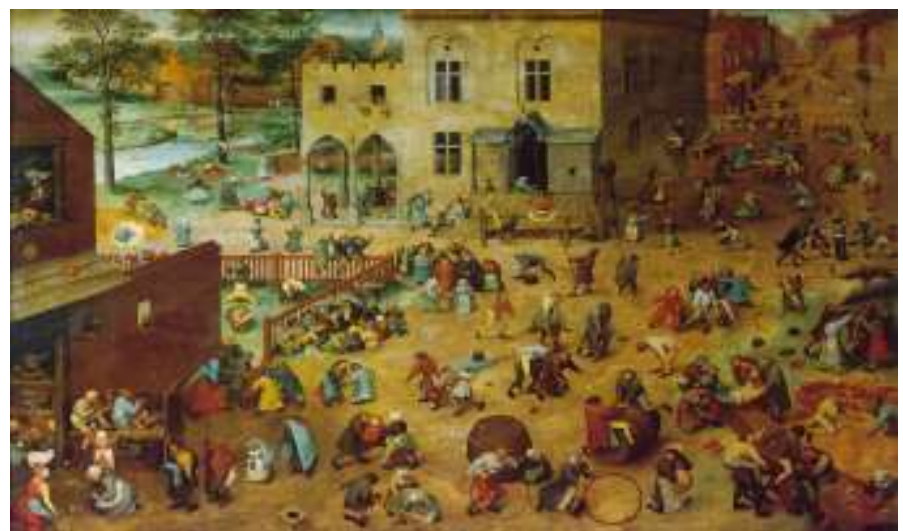

Figura 1 - Tela Jogos Infantis do artista Bruegel de 1560

Fonte: www1.folha.uol.com.br

Assim, consideramos que o uso de imagens voltado para além do cunho meramente ilustrativo pode ser uma ótima ferramenta didática no processo ensino-aprendizagem para 
todos os componentes curriculares. Principalmente se houver uma contextualização do conteúdo, pois segundo Darido (2002, p.153) "o conteúdo contextualizado propicia aprendizagens significativas que mobilizam o estudante, estabelecendo uma relação de reciprocidade entre ele e o objeto do conhecimento".

Durante este primeiro encontro, percebemos que algumas atitudes dos alunos evidenciaram o seu envolvimento corporal com a aula, como a realização de várias perguntas durante e após a aula, como também, os comentários e as reações de animação e euforia quando apareciam nos slides imagens ou fotos de jogos e brincadeiras que faziam parte da cultura de movimento deles, demonstrando reações de saudade e alegria. Para tanto, Zaboli, Bordas, e Lamar (2007, p. 52) afirmam que "a educação necessita, em suas formas de conceber as práxis pedagógicas, dar maior centralidade ao corpo, pois desta maneira irá transcender em vários sentidos rumo a um estágio de maior qualidade".

Preparamos o terreno para o encontro seguinte que teve como objetivos principais: $A$ vivência e compreensão do jogo enquanto manifestação da cultura do movimento; A experiência do jogo em suas manifestações competitiva, recreativa e cooperativa; A discussão sobre características do jogo como: espontaneidade, flexibilidade, criatividade, fantasia, prazer, divertimento, alegria, incerteza e imprevisibilidade de resultados. Percebemos que a formulação dos objetivos deve ir além da dinâmica das aulas, pois "as aprendizagens escolares tem que estar afinadas com as aprendizagens familiares e sociais, os conteúdos transmitidos de geração para geração e os socialmente acumulados têm que estar em sintonia e ter sentido para o aluno" (ARAGÃO, 2006, p.143). Por isso, orientamos aos alunos que procurassem conversar com familiares e amigos sobre os jogos e brincadeiras que fizeram parte de suas histórias, como também, buscassem informações sobre a realidade das crianças de hoje.

Inicialmente realizamos uma roda de conversa e contextualizamos um pouco sobre o que e como aconteceria a aula e os respectivos objetivos traçados para aquele dia. Daí por diante, apresentamos alguns jogos e brincadeiras bastante utilizados nas aulas de Educação Física como "pega-pega" e "corridas de revezamento", buscando mostrar a forma tradicional do jogo, como também, algumas variações, mas principalmente orientando-os a criarem e recriarem regras e formas de jogar, estimulando a criatividade, pois segundo Freire (1996, p. 22) "ensinar não é transferir conhecimento, mas criar as possibilidades para a sua produção ou a sua construção". Vivenciamos também, algumas atividades incomuns a cultura de movimento daqueles alunos como o jogo do "par ou impar", pois com esta e outras atividades despertamos a curiosidade e a sede nos alunos de conhecerem outras atividades para além dos conteúdos hegemônicos ligados ao ensino dos esportes como futebol, voleibol, handebol e basquetebol.

No fim do encontro nos reunimos novamente para fechar o momento e refletir um pouco sobre alguns aspectos vivenciados. Nesta roda de conversa foi solicitado aos alunos que expressassem as atividades que mais e menos tinham gostado; que destacassem as atividades que não conheciam; que falassem como tinham se sentido; que relacionassem os conhecimentos tecidos na aula anterior com o que foi vislumbrado naquele encontro entre outros questionamentos. Sobre este último queremos destacar que alguns alunos classificaram as atividades vivenciadas a partir das dimensões do jogo, como também, outros 
destacaram que a experimentação de algumas características como imprevisibilidade, flexibilidade e criatividade. Construímos este momento de partilha, pois estamos conscientes de que "é a realidade do corpo que nos permite sentir e, portanto, perceber o mundo, os objetos, as pessoas. É a realidade do corpo que nos permite imaginar, sonhar, desejar, pensar, narrar, conhecer, escolher" (NÓBREGA, 2010, p. 11).

Chegamos à comprovação também, de que o nível (de complexidade/exigência) de cada brincadeira e jogo deve ser adaptado ao nível (de compreensão/habilidade) dos seus respectivos executantes. Assim, concluímos o segundo encontro tirando algumas dúvidas e esclarecendo alguns pontos essenciais para a apresentação dos seminários que foram realizados no encontro subseqüente.

Os alunos receberam tanto no primeiro, como no segundo encontro a missão/orientações para fazerem uma pesquisa/inventário sobre os jogos e brincadeiras da cultura de movimento da região, ligados as suas experiências vividas. Para tanto, foram divididos nos grupos: jogos e brincadeiras atuais, jogos e brincadeiras de antigamente, brinquedos atuais e brinquedos de antigamente. Ficou estabelecida a entrega de uma via impressa do trabalho, como também, a apresentação de cada grupo no terceiro encontro deste relato. Este momento objetivou aprofundar as discussões, e envolver os alunos ainda mais no processo de construção do conhecimento, pois segundo Freire $(1996$, p.25) "não há ensino sem pesquisa e pesquisa sem ensino".

Queremos destacar que a maioria dos grupos se envolveu com o processo de construção dos trabalhos, pois presenciamos apresentações de alunos que foram a campo, buscaram entrevistar parentes e amigos, tiraram fotos, editaram vídeos, prepararam slides e cartazes, levaram brinquedos para expor, dentre outras ferramentas pedagógicas. Das inúmeras situações de aprendizagem que aconteceram ao longo dos seminários iremos discutir neste artigo apenas uma.

Esta situação aconteceu em um grupo que teve o tema "brinquedos atuais". Durante as considerações finais os componentes estavam apresentando os benefícios e malefícios que o uso dos jogos eletrônicos pode trazer aos seus adeptos. Ao referirem-se aos malefícios provocados pelo seu uso exacerbado, um dos alunos passou a contextualizar sobre uma criança de aproximadamente dez anos de idade que morava próxima a sua residência, e que por ser criada dentro da "lan house" de seu pai, passou a ter comportamentos "esquisitos", não sabendo diferenciar o mundo real do virtual. Sobre essa questão Le Breton (2003, p. 142) nos esclarece que o mundo virtual "as fronteiras se misturam e em que o corpo se apaga, em que o outro existe na interface da comunicação, mas sem corpo, sem rosto, sem outro toque além do teclado do computador, sem outro olhar além do olhar da tela".

O mesmo aluno mais adiante declarou que tinha muitas histórias pra contar (devido às brincadeiras de sua infância) e que sempre gostou de jogar vídeo-game, mas que nunca o priorizou em detrimento das brincadeiras na rua. E fazendo uma analogia com as crianças de hoje questiona: "O que a criançada de hoje tem pra contar? Né?! Passei um arquivo por Bluetooth?"

Ao refletir sobre o processo de ensino-aprendizagem presente na narrativa acima, compreendemos que a contextualização do conteúdo feita pelo aluno, nos aponta um 
indicativo rumo à construção de aprendizagens significativas, pois segundo Darido e Souza Junior (2007, p. 19):

As visões, fantasias, e decisões sobre o próprio corpo e a saúde, base para um desenvolvimento autônomo, poderão ser bem mais orientadas se as aprendizagens escolares estiverem relacionadas significativamente com as preocupações comuns na vida de todo jovem - preocupações como a aparência, sexualidade e reprodução, hábitos de alimentação... impostos pela mídia e pelo contexto. Caberá ao professor de educação física reconhecer e estar atento a esses temas, revendo cientificamente a importância dessas questões e passando a tratá-las pedagogicamente em suas aulas, de um modo que torne a aprendizagem mais significativa para os alunos".

Nesse sentido, temos buscado planejar e construir aulas a partir dos conhecimentos prévios dos alunos, como também, das experiências que os mesmos trazem ou tem demonstrado maior interesse. Temos consciência que precisamos avançar em pontos primordiais como o planejamento participativo e a dinâmica da avaliação como um todo, entre outros aspectos. Pois acreditamos que "extraindo do cotidiano do aluno os temas significativos, o professor tem em mãos o eixo central do programa educativo a desenvolver" (ARAGÃO, 2006, p.146).

\section{CONSIDERAÇÕES FINAIS}

As reflexões tecidas ao longo deste artigo giraram em torno do corpo, da aprendizagem e da cultura de movimento. Procuramos contextualizar como esse corpo tem sido tratado na educação e concebemos algumas críticas no tocante a imobilidade corporal e a segregação do corpo ao longo do processo educativo.

Apresentamos ainda a compreensão de que a aprendizagem deve ser compreendida como um ato corporal e não apenas intelectual a partir da leitura de autores como Maturana, Assmann e Nóbrega. Procuramos também, a partir de um relato de experiência com o ensino do conteúdo jogo em aulas de Educação Física no ensino médio trazer alguns apontamentos para a construção de aprendizagens significativas na escola.

No momento, não podemos afirmar se a experiência pedagógica discutida neste estudo foi significativa ou não para aqueles alunos, pois entendemos que aprendizagem significativa diz respeito ao que permanece, ao que cada um leva para a sua vida, ao que marca positiva ou negativamente o corpo dos envolvidos neste processo de ensinoaprendizagem. Por isso, quem sabe daqui a alguns anos possamos nos reencontrar em outros espaços dentro ou fora do ambiente escolar e conversarmos sobre essas e outras experiências que a Educação Física tenha os possibilitado.

As discussões em torno do corpo não são recentes no âmbito da Educação e nem tampouco na Educação Física, todavia acreditamos que precisamos materializar mais estudos que extrapolem os olhares dicotômicos que persistem na atualidade devendo o corpo ser 
compreendido como "condição de nossa existência não apenas biológica, mas também social e histórica" (NÓBREGA, 2010, p.37).

Defendemos que para atingirmos uma educação integral do ser humano é necessário quebrarmos alguns paradigmas que ainda estão cristalizados e em evidência na educação como a famosa frase do filósofo francês René Descartes "penso logo existo". Na verdade discordamos desta famosa frase e recorremos a Freire (2008, p. 71) quando o autor esclarece que "eu não existo porque penso, mas porque vivo. Minha existência não se faz sem corpo, porque sou corpo. O corpo que sou é a expressão de minha existência nesse mundo, e nada posso realizar se não agir corporalmente".

Os desafios estão lançados para a construção de uma educação inscrita no corpo. Porém Nóbrega (2010, p.12) nos alerta que "considerar o corpo na educação para além do aspecto racionalista ou instrumental, é uma tarefa que exige um exame radical de nossa relação com os afetos, com a linguagem, com a sexualidade, com a arte, com a cultura de um modo geral". Assim cabe a todos os componentes curriculares e não apenas a Educação Física e Artes estabelecerem diálogos com o corpo na educação, pois "quem experimenta? Quem inventa? O corpo. Quem flutua, corre e voa, em êxtase arcangélico quando levita banhado pela intuição bem-aventurada? O corpo, sempre ele" (SERRES, 2004, p. 144).

\section{REFERÊNCIAS BIBLIOGRÁFICAS}

1. ARAGÃO, M. G. S. Ensino da educação física escolar: como abordar. Paidéia: Revista Brasileira de Ensino de Arte e Educação Física, Natal, v.1, n.1, p. 139-162, dez, 2006.

2. ARAÚJO, Ana Cristina de. Correr, saltar, lançar, dialogar: uma reflexão sobre corpo e aprendizagem nas aulas de Educação Física. Natal (RN), 2005. Dissertação (Mestrado) UFRN.

3. ANDRÉ, M. E. D. A. de, PASSOS, L. F. Avaliação Escolar: desafios e perspectivas. In: CASTRO, Amélia Domingues de; CARVALHO, Ana Maria Pessoa (Org.). Ensinar a Ensinar: didática para a escola fundamental e média. São Paulo: Pioneira Thompson, 2002.

4. $\quad$ ASSMANN, H. Metáforas novas para Reencantar a educação. Piracicaba: Unimep, 1996.

5. Rj: Vozes, 2007. 10a Ed.

Reencantar a educação: Rumo à sociedade aprendente. Petrópolis,

6. BRACHT, V. A constituição das teorias pedagógicas em educação física. CADERNO CEDES. V. 19, n.48. p. 69-88. Campinas, ago.1999.

7. BEZERRA, M. de A., HERMIDA, J. F. Educação e Corporeidade: Vivências na Educação Infantil. EDUCAmazônia Educação, Sociedade e Meio Ambiente. Humaitá/AM , Ano 4 ,v. 7, n. 2, p. 74-91, jul-dez, 2011.

8. CARVALHO, A. M. P. de, PEREZ D. G. O saber e o saber fazer do professor. In: CASTRO, Amélia Domingues de; CARVALHO, Ana Maria Pessoa (Org.). Ensinar a Ensinar: didática para a escola fundamental e média. São Paulo: Pioneira Thompson, 2002.

9. CHIZZOTTI, A. Pesquisa em ciências humanas e sociais. São Paulo: Cortez, 1995. 
10. DARIDO, S. C.. In: PCN + Ensino Médio: Orientações Educacionais complementares aos Parâmetros Curriculares Nacionais. Brasília: MEC/ SEMTEC, 2002.

11. DARIDO, S. C., SOUZA JUNIOR, O. M. de. Para ensinar educação física: possibilidades de intervenção na escola. Campinas, SP: Papirus, 2007.

12. DIAS, M. A., MELO, J. P. A Pedagogia Freinet e a Relação Corpo e Aprendizagem na Educação. EDUCAmazônia Educação, Sociedade e Meio Ambiente. Humaitá/AM , Ano 4 ,v. 7, n. 2, p. 28-44 jul-dez, 2011.

13. FREIRE, J. B. Um mundo melhor, uma outra Educação Física. In: Os valores e as atividades corporais. David Rodrigues (Org). São Paulo: Summus, 2008.

14. FREIRE, P. Pedagogia da autonomia: saberes necessários à prática educativa. São Paulo: Paz e Terra, 36a ed, 1996.

15. GREINER, C. O corpo. CIDADE?.Annablume, 2005.

16. KUNZ, E. Educação Física. Ensino e mudanças. ljuí, Ed. Unijuí, 1998.

17. LE BRETON, David. Adeus ao Corpo: Antropologia e sociedade. Campinas: Papirus; 3a Edição, 2003.

18. MARTINS, A. G. e THEÓPHILO, C. R. Metodologia da investigação científica para ciências sociais aplicadas. São Paulo, Ed. Atlas S.A., 2007.

19. MATURANA, H. R. Cognição, ciência e vida cotidiana. Org e Trad: Cristina Magro e Victor Praxedes. Editora UFMG, Belo Horizonte, 2001.

20. MELO, J. P. de. Fundamentos Metodológicos da Consciência Corporal aplicados à Cultura de Movimento. Projeto Integrado. Natal: UFRN, 2002.

21. NEIRA, M. G., NUNES, M. L. F. Educação Física, Currículo e Cultura. São Paulo, editora Phorte, 2009.

22. NÓBREGA, Terezinha Petrúcia da. Corporeidade e educação física: do corpo objeto ao corpo sujeito. 2a Edição, Natal, RN: EDUFURN, 2005.

23.

Livraria da Física, 2010. Uma Fenomenologia do corpo. São Paulo: Editora

24. SERRES, M. Variações sobre corpo. Trad. Edgard de Assis Carvalho e Mariza Perassi Bosco. Rio de Janeiro: Bertrand Brasil, 2004.

25. SOUZA JÚNIOR, M., MELO, M. S. T., SANTIAGO, M. E. A análise de conteúdo como forma de tratamento dos dados numa pesquisa qualitativa em Educação Física escolar. Revista Movimento, Porto Alegre, v. 16, n.3, p. 31-49, julho/setembro de 2010.

26. ZABOLI, F., BORDAS, M. A. G., LAMAR, A. R. A mente como alvo do processo de ensino/aprendizagem: a escola e a educação física como focos de análise. Paidéia: Revista Brasileira de Ensino de Arte e Educação Física, Natal, v.1, n.1, p. 35-55, dez. 2007. 